\title{
Magnetic resonance imaging of the temporomandibular joint acquired using different parameters
}

\author{
ALONSO, M. B. C. C. ${ }^{1}$, GAMBA, T. O. ${ }^{1}$, LOPES, S. L. P. C. ${ }^{2}$, CRUZ, A. D. $^{3}$, \\ FREITAS, D. Q. ${ }^{1}$ and HAITER-NETO, F. ${ }^{1}$ \\ ${ }^{1}$ Department of Oral Diagnosis, School of Dentistry, University of Campinas - UNICAMP, CEP 13414-903, \\ Piracicaba, SP, Brazil \\ ${ }^{2}$ Department of Diagnosis and Surgery, São José dos Campos Dental School, São Paulo State University - UNESP, \\ CEP 12245-000, São José dos Campos, SP, Brazil \\ ${ }^{3}$ Area of Radiology, Department of Specific Formation, Nova Friburgo Dental School, Fluminense Federal \\ University - UFF, CEP 24020-150, Nova Friburgo, RJ, Brazil \\ ${ }^{*}$ E-mail: mbalonso@fop.unicamp.br
}

\begin{abstract}
Introduction: Magnetic resonance imaging (MRI) is considered the examination of choice for the diagnosis of abnormalities in the TMJ. Considering the difficulty in defining and standardizing the diagnostic criteria, and the need for more accurate and reliable diagnosis of conditions in the TMJ, the aim of the present study was to compare three different MRI parameters: T1-weighted, T2-weighted and proton density-weighted in the diagnosis of changes in the temporomandibular joint. Materials and Methods: Fifty magnetic resonance imaging examinations of the temporomandibular joint (100 temporomandibular joints) were conducted according to a protocol that evaluates disc position, disc function and bone abnormalities. The images were obtained bilaterally in parasagittal sections in closed and open mouth positions in the three studied parameters Three trained oral radiologists assessed all the images. Reliability of the intra- and inter-examiner response was analyzed using the concordance test (Fleiss' kappa; $\alpha=0.05$ ). Results: The reliability of the response patterns between observers for different protocols varied from very good to good. Observers were less constant in their response patterns when assessing proton density-weighted images. There was very good agreement for disc morphology, cortical bone and bone structures/functions; however, there was wide variation for medullary bone marrow signs. Conclusion: T2-weighted imaging was found to be the best examination to assess the medullary bone. For evaluating of disc morphology, cortical bone and bone structures/functions, any protocol is indicated once the protocol does not interfere with the analysis.
\end{abstract}

Keywords: temporomandibular joint, magnetic resonance imaging, temporomandibular joint disorders, mandibular condyle, temporomandibular articular disc.

\section{Introduction}

The temporomandibular joint (TMJ) is the joint between the jaw and the skull, more specifically, the mandibular condylar process with the temporal bone, with the space between the two bones occupied by an articular disc (MANFREDINI, BONNINI, STELLINI et al., 2014). Several structural changes may involve the mandible head and/or the articular disc (SESSLE 2009; ALMĂŞAN, HEDEŞIU, BĂCIUŢ et al., 2013; WANGSRIMONGKOL, MANOSUDPRASIT, PISEK et al., 2013), therefore physical examination alone has been reported to be inefficient for determining a clinical diagnosis for the TMJ (LARHEIM, WESTESSON and SANO, 2001; SANO, YAMAMOTO, OKANO et al., 2004). Magnetic resonance imaging (MRI) is considered the examination of choice for the diagnosis of abnormalities in the TMJ; the articular disc can be seen and the cortex, marrow, hyaline cartilage, muscle, fluid and fibrous tissue can be differentiated. Inherent soft tissue discrimination (vague) allows acquisition of thin sections and the development of faster imaging techniques and dualcoil imaging has facilitated bilateral examination of the TMJ (TASALI, CUBUK, ARICAK et al., 2012; MANFREDINI,
BONNINI, STELLINI et al., 2014; ALMĂŞAN, HEDEŞIU, BĂCIUȚ et al., 2013).

In order to show the different tissues and structures, MRI protocols with specific acquisition parameters are normally used to examine the behaviour of particular components of a structure. In addition, depending on the acquisition parameters, certain morphological and pathologic conditions can be visualized in different ways. Thus, MR images may be captured in three forms: the first, a Tl-weighted image, is used not only to assess normal anatomy but also to evaluate disorders mainly after administration of contrast medium; T2-weighted images are normally used to evaluate tissues that exhibit changes, in this case the presence of swelling and high vascularization of the tissue lead to a very intense signal on T2-weighted images; and Proton density (PD)weighted images have characteristics intermediate between T1-weighted and T2-weighted images and are therefore very useful for visualization of menisci and ligaments are used in protocols for assessing muscle (LOPES, COSTA, CRUZ et al., 2012; ALMĂŞAN, HEDEŞIU, BĂCIUȚ et al., 2013). 
The TMJ has benefited enormously from the development of MRI in the field of diagnostic imaging because it is a noninvasive method with no ionizing radiation effects. MRI provides high-definition images of the condyle, articular fossa and eminence, articular disc and structures around them, so MRI is therefore one of the best imaging modalities for detecting alterations in the TMJ (COZZOLLINO, RAPOPORT, FRANZI et al., 2008; LOPES, COSTA, CRUZ et al., 2012). However, the different types of imaging protocols are not equally effective for detecting the changes that can affect the TMJ. The efficacy of a specific protocol depends mainly on diagnostic accuracy, which is a complex interaction between the image and the person evaluating and interpreting the image (BROOKS, BRAND, GIBBS et al., 1997; LOPES, COSTA, CRUZ et al., 2012).

Several studies in the literature report changes in the TMJ using MRI, and many use a combination of images acquired using only two parameters (COZZOLLINO, RAPOPORT, FRANZI et al., 2008; LOPES, COSTA, CRUZ et al., 2012; ALMĂŞAN, HEDEŞIU, BĂCIUŢ et al., 2013) but, until recently, no scientific study has evaluated and compared the efficiency of diagnosing changes in the TMJ using three imaging acquisition parameters. Therefore, advancing our understanding of the prevalence, cause, diagnosis, natural progression and treatment of changes in the TMJ depends on the reliability and validity of the diagnostic criteria (SCHIFFMAN, TRUELOVE, OHRBACH et al., 2010).

Because of the difficulty in defining and standardizing the diagnostic criteria (SESSLE, 2009), and the need for more accurate and reliable diagnosis of conditions in the TMJ, the aim of this study was to compare the different types of acquisition protocols for MRI (Tl-weighted, T2-weighted and PD) in the diagnosis of changes in the temporomandibular joint by assessing the position and morphology of the articular disc as well as of the bone components of the TMJ. We attempt to clarify what parameter is better to elucidate the each studied condition.

\section{Materials and Methods}

This retrospective study was approved by the Human Ethical Committee. Fifty MRI examinations of the TMJ (100 TMJs) from individuals of both sexes, aged between 18 and 75 years (mean 43.5 years) who had undergone an MRI scan in the previous 12 months, according to different indications, were reviewed.

\section{$2.1 M R I$}

All images were acquired in a Medical System unit (General Electric, Milwaukee, WI, USA), which has a magnetic field rated at $1.5 \mathrm{~T}$, using a TMJ $7.5-\mathrm{cm}$ dual-surface coil and the following parameters: Tl-weighted spin-echo (TlW) sequences, repetition time (TR) $300.0 \mathrm{~ms}$, echo time (TE) $12.7 \mathrm{~ms}$, matrix $512 \times 512$, echo time 4 , thickness $3 \mathrm{~mm}$, field of view $(\mathrm{FOV}) 15 \times 15 \mathrm{~cm}$; T2-weighted spin-echo (T2W) sequences, TR $1500.0 \mathrm{~ms}$, TE, $107.0 \mathrm{~ms}$, matrix 512 $\times 512$, echo time 18 , thickness $3 \mathrm{~mm}$, FOV $15 \times 15 \mathrm{~cm}$; PD fat-suppression-weighted (PDW) sequences, TR $1016.7 \mathrm{~ms}$, TE $14.2 \mathrm{~ms}$, matrix $512 \times 512$, echo time 4 , thickness $3 \mathrm{~mm}$, FOV $15 \times 15 \mathrm{~cm}$. All examinations were performed without sedation and without contrast injection in the joints.
In each examination, axial localizer TIW images were obtained in the closed mouth position in order to obtain the real long axis of each right and left condyle. The parasagittal images (perpendicular to the central part of the long axis of each condyle) were then planned and considered for analysis. The parasagittal images were obtained in the closed and open mouth positions using the three different parameters: T1W, T2W and PDW (Figure 1). Thus, for each TMJ, 6 sets of central parasagittal images were evaluated: $\mathrm{Tl}$ in closed and open mouth positions, T2W images in closed and open mouth positions and PDW in closed and open mouth positions. The images were evaluated separately by three oral radiologists, each with 10 years experience in maxillofacial radiology and in diagnostic MRI examinations. The images were interpreted dynamically by each radiologist. The examiners were blinded to the results and had previously evaluated images during a calibration session. The images were interpreted on a monitor under appropriate conditions with suitable brightness.

\subsection{Image evaluation}

The images were evaluated using the following protocol:

(a) The position of the articular disc on closed mouth images was classified as follows: normal when the location of the posterior band of the disc was in the superior portion of the condyle, or the 12 o'clock position relative to the condyle; displaced when the posterior band of the disc was anterior to the superior part of the condyle (TASAKI, WESTESSON, ISBERG et al., 1996) (Figure 2b);

(b) The position of the articular disc on open mouth images was classified as follows: reduction when the intermediate portion of the articular disc was located between the vertex of the eminence and the condyle (Figure 2a); or not reduced when there was no articular disc between the eminence and the condyle;

(c) The mobility of the condyle was classified as follows: normal when the condyle was positioned close to the apex of the eminence at the maximum open mouth position; hypomobility when the condyle at the maximum open mouth position was positioned behind the eminence vertex; hypermobility when the condyle at the maximum open mouth positions was positioned in front of and above the eminence vertex (Figure 2d);

(d) Visualization of the cortical bone (the condyle, mandibular fossa and articular eminence) was classified as follows: continuous when the hyposignal of the cortical bone showed no interruptions; discontinuous or thickened when the hyposignal showed interruptions or thickened areas, respectively;

(e) The condyle medullary bone signal was normal when the medullary showed a hypersignal on the TlW image, a hyposignal on the T2W image, and an intermediate signal on the PDW image. Otherwise it was considered abnormal (Figure 2e);

(f) Morphology of the articular disc was normal when the three zones (posterior, intermediate and anterior) were distinguishable in the images. The articular disc signal was normal when it presented a hyposignal in all images;

(g) Flattening of the mandibular condyle was either present or absent; 


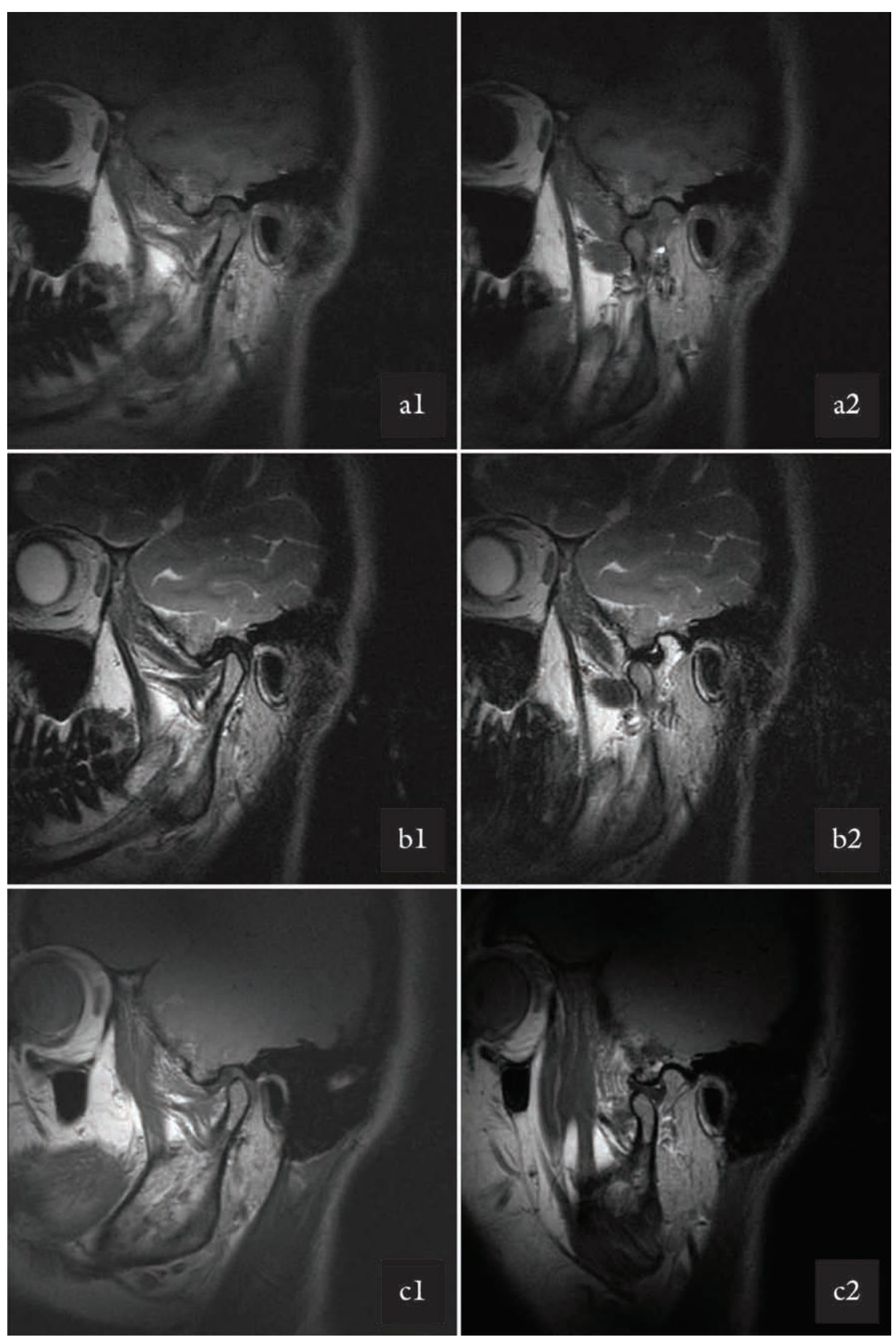

Figure 1. Examples of images in the parasagittal plane: al, T1W closed mouth position; a2, T1W open mouth position; bl, T2W closed mouth position; b2, T2W open mouth position; c1, PDW closed mouth position; c2, PDW open mouth position. 

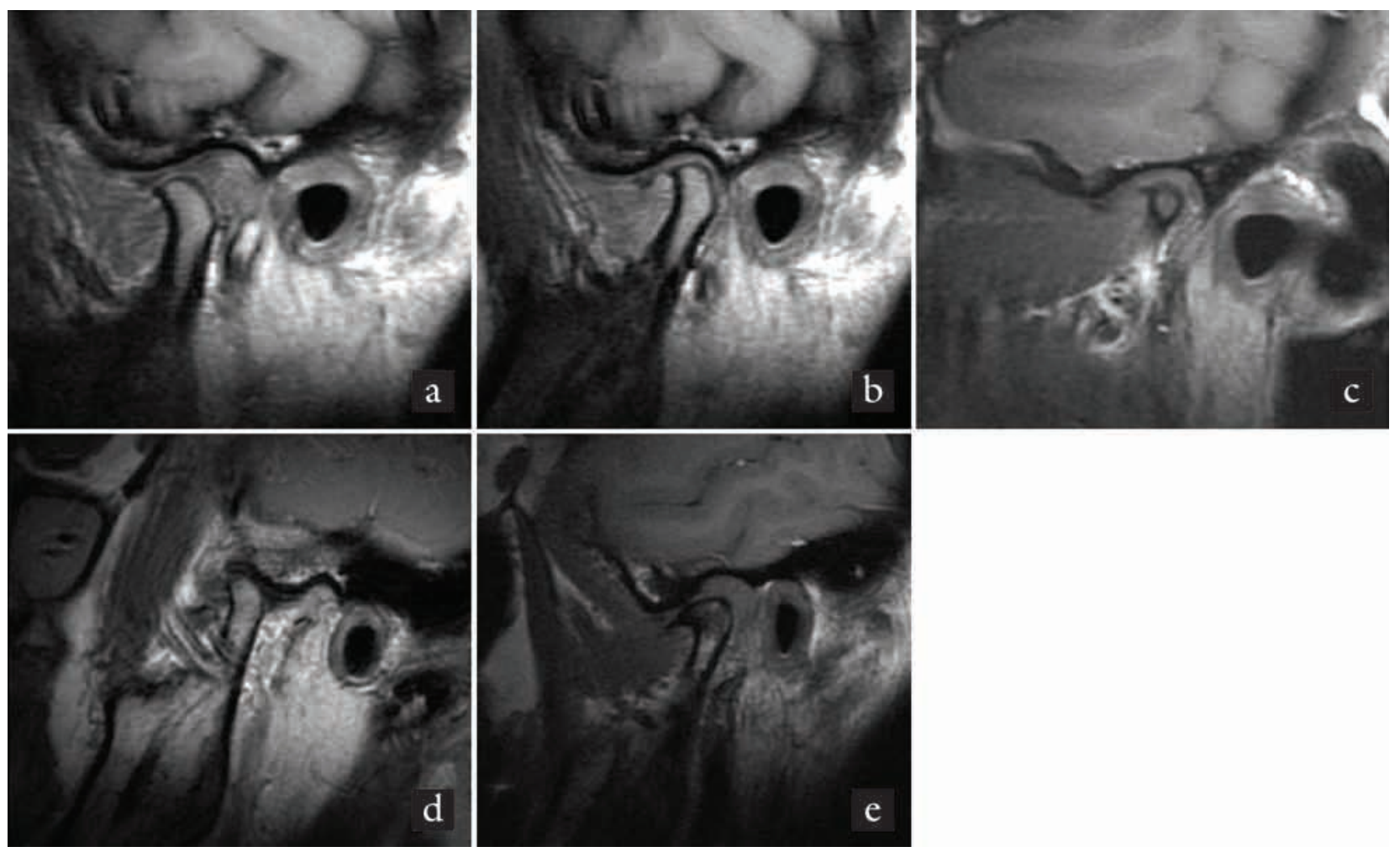

Figure 2. Examples of images in the parasagittal plane (zoom) for different subjects showing: (a) normal disc position (reduction) in the open mouth position (T1W); (b) disc displacement in the closed mouth position (T1W); (c) osteophyte (PDW); (d) hypermobility (T2W); (e) osteophyte and medullary necrosis (T1W).

(h) Osteophytes were present when there was bone formation in the condyle cortical thickness with the same convex shape, similar to a duckbill, or absent (Figure $2 \mathrm{c}$ and $2 \mathrm{e}$ ).

\subsection{Statistical methods and analyses of the results}

The reliability of intra-examiner response patterns based on individual responses to images from different modalities and inter-examiner response based on the response of the group to the same imaging modality were analyzed using the Fleiss kappa test. All statistical analyses were conducted using the Stata Statistics/Data Analysis version 11.0 software (StataCorp, Texas, USA) with the significance level set at $5 \%$ $(\alpha=0.05)$.

\section{Results}

Table 1 shows very good and good agreement for the intraexaminer response patterns for different imaging modalities. Examiner 1 showed a higher strength of agreement in their response patterns than Examiner 2. There was very good and good agreement between the inter-examiner response patterns for the same imaging modality.

Table 2 shows the high variability of the examiners' response patterns for different imaging modalities for the individual variables. The variables disc closed mouth, disc open mouth, bone cortical-articular eminence, osteophyte showed very good agreement between different imaging modalities. The variables mobility, condyle cortical bone, cortical bone-articular eminence, articular disc signal, flattening of the condyle show very good and good agreement; the variable cortical bone-mandibular fossa show great variability in the response patterns from good agreement to fair agreement, indicating that the observer had difficulty with this diagnosis. There was poor agreement for the bone marrow signal variable indicating that the observers were not able to agree; however, when we evaluated each parameter singly, T2W imaging was found to be the most appropriate because it showed greater agreement among the raters $(89.3 \%)$.

MRI is currently considered the gold standard for evaluation of the TMJ, articular disc and its bone components (TASAKI, WESTESSON, ISBERG et al., 1996; BROOKS, BRAND, GIBBS et al., 1997; COZZOLLINO, RAPOPORT, FRANZI et al., 2008; SCHIFFMAN, TRUELOVE, OHRBACH et al., 2010; TASALI, CUBUK, ARICAK et al., 2012; MANFREDINI, BONNINI, STELLINI et al., 2014; ALMĂŞAN, HEDEŞIU, BĂCIUȚ et al., 2013). Greater understanding of the prevalence, causes, treatment and natural history of temporomandibular disorders depends directly on the reliability and validity of the diagnostic criteria (SCHIFFMAN, TRUELOVE, OHRBACH et al., 2010). Thus, the present study compares the performance of three image acquisition parameters (T1W, T2W and PDW) by evaluating the articular disc (position and function) and the presence of bone changes (cortical and medullary) and TMJ components; the more images required, the greater is the total examination time and the possible discomfort for the patient as well as chances of negative effects (claustrophobia, movements, etc.). 
Table 1. Reliability of the intra- and inter-observer response patterns.

\begin{tabular}{|c|c|c|c|c|c|c|c|}
\hline Analysis & & Tariables & Agreement (\%) & Kappa & Standard & $Z$ & Prob $>Z$ \\
\hline \multirow[t]{9}{*}{ Intra-observer } & Obsl & $\mathrm{PDW} \times \mathrm{TlW}$ & 92.0 & $0.82^{\mathrm{a}}$ & 0.04 & 18.38 & 0.00 \\
\hline & & $\mathrm{PDW} \times \mathrm{T} 2 \mathrm{~W}$ & 91.2 & $0.81^{\mathrm{a}}$ & 0.04 & 18.23 & 0.00 \\
\hline & & $\mathrm{T} 1 \mathrm{~W} \times \mathrm{T} 2 \mathrm{~W}$ & 90.4 & $0.79^{\mathrm{b}}$ & 0.04 & 17.91 & 0.00 \\
\hline & Obs2 & $\mathrm{PDW} \times \mathrm{T} 1 \mathrm{~W}$ & 87.2 & $0.71^{\mathrm{b}}$ & 0.04 & 15.89 & 0.00 \\
\hline & & $\mathrm{PDW} \times \mathrm{T} 2 \mathrm{~W}$ & 84.8 & $0.67^{\mathrm{b}}$ & 0.04 & 15.12 & 0.00 \\
\hline & & $\mathrm{T} 1 \mathrm{~W} \times \mathrm{T} 2 \mathrm{~W}$ & 85.2 & $0.68^{\mathrm{b}}$ & 0.04 & 15.35 & 0.00 \\
\hline & Obs3 & $\mathrm{PDW} \times \mathrm{T} 1 \mathrm{~W}$ & 89.8 & $0.77^{\mathrm{b}}$ & 0.04 & 17.29 & 0.00 \\
\hline & & $\mathrm{PDW} \mathrm{X} \times \mathrm{T} 2 \mathrm{~W}$ & 88.0 & $0.75^{\mathrm{b}}$ & 0.04 & 16.78 & 0.00 \\
\hline & & $\mathrm{T} 1 \mathrm{~W} \times \mathrm{T} 2 \mathrm{~W}$ & 87.8 & $0.74^{\mathrm{b}}$ & 0.04 & 16.73 & 0.00 \\
\hline \multirow[t]{9}{*}{ Inter-observer } & PDW & Obs $1 \times$ Obs 2 & 86.4 & $0.70^{\mathrm{b}}$ & 0.04 & 15.63 & 0.00 \\
\hline & & Obsl $\times$ Obs 3 & 94.8 & $0.89^{a}$ & 0.04 & 19.80 & 0.00 \\
\hline & & Obs $2 \times$ Obs 3 & 84.0 & $0.65^{\mathrm{b}}$ & 0.04 & 14.44 & 0.00 \\
\hline & $\mathrm{TlW}$ & Obs $1 \times$ Obs 2 & 88.8 & $0.74^{\mathrm{b}}$ & 0.04 & 16.59 & 0.00 \\
\hline & & Obs1 1 Obs3 & 97.4 & $0.94^{\mathrm{a}}$ & 0.04 & 21.04 & 0.00 \\
\hline & & Obs $2 \times$ Obs 3 & 88.6 & $0.74^{\mathrm{b}}$ & 0.04 & 16.53 & 0.00 \\
\hline & $\mathrm{T} 2 \mathrm{~W}$ & Obs $1 \times$ Obs 2 & 89.6 & $0.78^{\mathrm{b}}$ & 0.04 & 17.47 & 0.00 \\
\hline & & Obs $1 \times$ Obs3 & 97.2 & $0.94^{\mathrm{a}}$ & 0.04 & 21.06 & 0.00 \\
\hline & & Obs $2 \times$ Obs 3 & 87.6 & $0.74^{\mathrm{b}}$ & 0.04 & 16.58 & 0.00 \\
\hline
\end{tabular}

Strength of agreement in accordance with the kappa values: ${ }^{\mathrm{a}} \mathrm{very} \operatorname{good}(1.00 \leq k \geq 0.81)$; ${ }^{\mathrm{b}} \operatorname{good}(0.80 \leq k \geq 0.61)$; ${ }^{\mathrm{c}}$ moderate $(0.60 \leq k \geq 0.41)$; dfair $(0.40 \leq k \geq 0.21)$; ${ }^{\mathrm{c}}$ poor $(k \leq 0.20)$.

TlW imaging is used routinely and is ideal for revealing general anatomic detail with marrow signal enhancement; T2W images emphasize the existence of possible changes such as the presence of oedema, joint effusion, and oedema at the bone marrow. In addition to these routine protocols, PDW images show hybrid characteristics, enabling high definition even in lesions of the articular disc, PDW and TIW images tend to reveal the gross anatomy more clearly than T2W images (LOPES, COSTA, CRUZ et al., 2012). However, because of the complexity of the signal, the potential difficulty in interpreting the images and the limited value for visualizing bone and bone densities can be considered drawbacks. Styles and Whyte (2002) suggest that parasagittal and paracoronal TIW and PDW images in the closed mouth position are ideal for evaluating joint anatomy. In the present study, we found that the variable bone marrow signal showed poor concordance between examiners, and the diagnosis of medullary conditions is thus influenced by the chosen protocol; T2W imaging showed greater agreement among raters.

Regarding the analysis of medullary signs, it is sometimes necessary to compare images acquired using two sets of parameters. Normally, the bone marrow is seen with hyperintense TIW imaging and a less intense signal is seen on T2W imaging. Reversal of these characteristics, that is, a hypointense signal on TlW imaging and a hyperintense signal on T2W imaging, indicates the possible presence of medullary oedema, but it does not rule out other changes, such as the presence of necrosis or subchondral cysts, which are well visualized on TIW images or even PDW images. What we mean by this is that the variable component of the bone marrow signal in the TMJ is a differentiating factor and discordant in this study. Thus, there is a need for a comparative evaluation between two or more parameters, such as $\mathrm{T} 1 \mathrm{~W} / \mathrm{T} 2 \mathrm{~W}$ or $\mathrm{PDW} / \mathrm{T} 2 \mathrm{~W}$ to make a correct diagnosis. Just one set of images cannot provide an accurate diagnosis of the bone marrow, which justifies acquisition of images using different parameters with a longer examination time.

The signals reconstructed from MRI are complex and variable and have the potential to confuse a professional who does not have experience with this technique (LOPES, COSTA, CRUZ et al., 2012). In our study all the examiners were dentists or radiologists with more than 10 years of experience in this type of examination. Intra- and interexaminer reliability was very good and showed good diagnostic ability, demonstrating that MRI is a reliable method for the assessment of TMJ, in accordance with Almăşan, Hedeşiu, Băciuţ et al. (2013).

In the present study, the variables disc closed mouth (normal or displaced), disc open mouth (with or without reduction), cortical bone-articular tubercle (continuous, thickened, displaced) and osteophyte (present, absent) showed very good agreement between the parameters indicating that T1W, T2W or PDW can be used reliably in the diagnosis. Clinicians should observe carefully the variation in articular disc displacement, because this condition is shown as a precursor of future more serious changes, such as synovial proliferation and effusion. The present study demonstrates that this condition can be diagnosed regardless of the parameter chosen.

The lack of association of images with clinical data may be considered a limitation in the present study. Therefore, additional research focused on the relationship between the signs and symptoms of the clinical diagnosis and the results of MRI is necessary to better understand dynamic imaging of the TMJ using specific parameters. 
Table 2. Distribution of response patterns from each observer in accordance with the imaging modalities, mean agreement and mean kappa values (minimum and maximum values).

\begin{tabular}{|c|c|c|c|c|c|c|c|c|c|c|c|}
\hline \multirow{2}{*}{ Variables } & \multicolumn{3}{|c|}{ Observer 1} & \multicolumn{3}{|c|}{ Observer 2} & \multicolumn{3}{|c|}{ Observer 3} & \multirow{2}{*}{$\begin{array}{c}\text { Mean } \\
\text { agreement } \\
(\%)\end{array}$} & \multirow{2}{*}{$\begin{array}{c}\text { Mean kappa } \\
\text { values (min; } \\
\text { max) }\end{array}$} \\
\hline & PDW & T1W & $\mathrm{T} 2 \mathrm{~W}$ & PDW & T1W & $\mathrm{T} 2 \mathrm{~W}$ & PDW & T1W & $\mathrm{T} 2 \mathrm{~W}$ & & \\
\hline \multicolumn{12}{|c|}{ Disc: closed mouth } \\
\hline Normal & 34 & 33 & 32 & 39 & 38 & 36 & 34 & 33 & 31 & \multirow[t]{2}{*}{97.33} & $0.94^{\mathrm{a}}$ \\
\hline Displaced & 16 & 17 & 18 & 11 & 12 & 14 & 16 & 17 & 19 & & $(0.91 ; 0.95)$ \\
\hline \multicolumn{12}{|c|}{ Disc: open mouth } \\
\hline Reduction & 44 & 44 & 44 & 45 & 46 & 45 & 43 & 44 & 43 & \multirow[t]{2}{*}{100.00} & $1.00^{\mathrm{a}}$ \\
\hline $\begin{array}{l}\text { Without } \\
\text { reduction }\end{array}$ & 7 & 6 & 6 & 5 & 4 & 5 & 7 & 6 & 7 & & $(1.00 ; 1.00)$ \\
\hline \multicolumn{12}{|l|}{ Disc mobility } \\
\hline Normal & 39 & 40 & 40 & 33 & 37 & 32 & 39 & 38 & 40 & \multirow[t]{3}{*}{94.67} & $0.84^{\text {a.b }}$ \\
\hline Нуро & 11 & 10 & 10 & 17 & 13 & 18 & 11 & 12 & 10 & & $(0.77 ; 0.94)$ \\
\hline Hyper & 0 & 0 & 0 & 0 & 0 & 0 & 0 & 0 & 0 & & \\
\hline \multicolumn{12}{|c|}{ Mandibular condyle cortical bone } \\
\hline Continuous & 40 & 41 & 42 & 41 & 45 & 38 & 39 & 41 & 39 & \multirow[t]{3}{*}{94.67} & $0.82^{\mathrm{a} . \mathrm{b}}$ \\
\hline Thickened & 10 & 9 & 8 & 9 & 5 & 12 & 11 & 9 & 11 & & $(0.73 ; 0.93)$ \\
\hline Displaced & 0 & 0 & 0 & 0 & 0 & 0 & 0 & 0 & 0 & & \\
\hline \multicolumn{12}{|c|}{ Cortical bone-mandibular fossa } \\
\hline Continuous & 46 & 47 & 47 & 44 & 48 & 46 & 46 & 46 & 47 & \multirow[t]{3}{*}{94.67} & $0.53^{\mathrm{b}-\mathrm{d}}$ \\
\hline Thickened & 3 & 3 & 3 & 6 & 2 & 4 & 4 & 3 & 3 & & $(0.29 ; 0.65)$ \\
\hline Displaced & 0 & 0 & 0 & 0 & 0 & 0 & 0 & 1 & 0 & & \\
\hline \multicolumn{12}{|c|}{ Cortical bone-articular tubercle } \\
\hline Continuous & 46 & 45 & 46 & 45 & 45 & 45 & 46 & 45 & 44 & \multirow[t]{3}{*}{100.00} & $1.00^{\mathrm{a}}$ \\
\hline Thickened & 4 & 5 & 4 & 5 & 5 & 5 & 4 & 5 & 6 & & $(1.00 ; 1.00)$ \\
\hline Displaced & 0 & 0 & 0 & 0 & 0 & 0 & 0 & 0 & 0 & & \\
\hline \multicolumn{12}{|c|}{ Medullary bone signal } \\
\hline Hypersignal & 28 & 40 & 6 & 31 & 35 & 14 & 30 & 40 & 7 & \multirow[t]{2}{*}{38.67} & $-0.05^{\mathrm{e}}$ \\
\hline Hyposignal & 22 & 10 & 45 & 19 & 15 & 37 & 20 & 10 & 44 & & $(-0.18 ; 0.04)$ \\
\hline \multicolumn{12}{|c|}{ Articular disc signal } \\
\hline Normal & 45 & 45 & 43 & 45 & 46 & 45 & 44 & 45 & 43 & \multirow[t]{4}{*}{96.00} & $0.80^{a . b}$ \\
\hline Abnormal & 3 & 2 & 3 & 4 & 3 & 2 & 4 & 2 & 3 & & $(0.78 ; 0.81)$ \\
\hline Abnormal Form & 2 & 3 & 4 & 1 & 1 & 3 & 2 & 3 & 4 & & \\
\hline \multicolumn{11}{|l|}{ Osteophyte } & \\
\hline Present & 0 & 0 & 0 & 1 & 1 & 0 & 0 & 0 & 0 & \multirow[t]{2}{*}{100.00} & $1.00^{\mathrm{a}}$ \\
\hline Absent & 50 & 50 & 50 & 49 & 49 & 50 & 50 & 50 & 50 & & $(1.00 ; 1.00)$ \\
\hline \multicolumn{12}{|c|}{ Flattening of the mandibular condyle } \\
\hline Present & 4 & 3 & 4 & 6 & 3 & 5 & 5 & 3 & 4 & 97.33 & $0.81^{a . b}$ \\
\hline Absent & 46 & 47 & 46 & 44 & 47 & 45 & 45 & 47 & 46 & & $(0.73 ; 0.85)$ \\
\hline
\end{tabular}

Strength of agreement in accordance with the kappa values $(k)$ : ${ }^{a}$ very $\operatorname{good}(1.00 \leq k \geq 0.81) ;{ }^{b} \operatorname{good}(0.80 \leq k \geq 0.61) ;{ }^{c}$ moderate $(0.60 \leq k \geq 0.41)$; ${ }^{\mathrm{d}}$ fair $(0.40 \leq k \geq 0.21)$; ${ }^{\mathrm{c}}$ poor $(k \leq 0.20)$.

\section{Conclusion}

Based on the results of this study, it can be concluded that the diagnosis of medullary bone signs is influenced by the type of parameter used for the MRI examination. T2W is the best examination to assess medullary signs. To evaluate disc morphology/function, cortical bone and bone functions, the choice of any parameter (T1W, T2W or PDW) is indicated once the protocol did not interfere with the analysis.

\section{References}

ALMĂȘAN, OC., HEDEŞIU, M., BĂCIUȚ, G., LEUCUȚA, DC. and BĂCIUT, M. Disk and joint morphology variations on coronal and sagittal MRI in temporomandibular joint disorders. Clinical Oral
Investigations, 2013, vol. 17, n. 4, p. 1243-1250. PMid:22868824. http://dx.doi.org/10.1007/s00784-012-0803-4

BROOKS, SL., BRAND, JW., GIBBS, SJ., HOLLENDER, L., LURIE, AG., OMNELL, KA., WESTESSON, PL. and WHITE, SC. Imaging of the temporomandibular joint: a position paper of the American Academy of Oral and Maxillofacial Radiology. Oral Surgery, Oral Medicine, Oral Pathology, Oral Radiology, and Endodontics, 1997, vol. 83, n. 5, p. 609-618. PMid:9159823.

COZZOLLINO, FA., RAPOPORT, A., FRANZI, AS., SOUZA, RP., PEREIRTA, CAB. and DEDIVITIS, RA. Correlação entre os achados clínicos e imaginológicos nas disfunções temporomandibulares. Radiologia Brasileira, 2008, vol. 41, n. 1, p. 13-17. http://dx.doi.org/10.1590/S010039842008000100006 
LARHEIM, TA., WESTESSON, P. and SANO, T. Temporomandibular joint disk displacement: comparison in asymptomatic volunteers and patients. Radiology, 2001, vol. 218, n. 2, p. 428-432. PMid:11161157. http://dx.doi.org/10.1148/ radiology.218.2.r0lfel1428

LOPES, SL., COSTA, AL., CRUZ, AD., LI, LM. and ALMEIDA, SM. Clinical and MRI investigation of temporomandibular joint in major depressed patients. Dento Maxillo Facial Radiology, 2012, vol. 41, n. 4, p. 316-322. PMid:22517997 PMCid:PMC3729006. http://dx.doi.org/10.1259/dmfr/27328352

MANFREDINI, D., BONNINI, S., STELLINI, E., SALMASO, L. and GUARDA-NARDINI, L. Comparison of magnetic resonance imaging findings in temporomandibular joints of the two sides. Clinical Oral Investigations, 2014, vol. 18, n. 2, p. 499-506. PMid:23640716. http://dx.doi.org/10.1007/s00784-013-0984-5

SANO, T., YAMAMOTO, M., OKANO, T., GOKAN, T. and WESTESSON, PL. Commom abnormalities in temporomandibular joint imaging. Current Problems in Diagnostic Radiology, 2004, vol. 33, n. 1, p. 16-24. PMid:14712198. http://dx.doi. org/10.1016/j.cpradiol.2003.09.001

SCHIFFMAN, EL., TRUELOVE, EL., OHRBACH, R., ANDERSON, GC., JOHN, MT., LIST, T. and LOOK, JO. The research diagnostic criteria for temporomandibular disorders. I: overview and methodology for assessment of validity. Journal of Orofacial Pain, 2010, vol. 24, n. 1, p. 7-24. PMid:20213028 PMCid:PMC3157055.

SESSLE, BJ. A focus on the research diagnostic criteria for temporomandibular disorders. Journal of Orofacial Pain, 2009, vol. 23, n. 1, p. 5-6. PMid:19264031.
STYLES, C. and WHYTE, A. MRI in the assessment of internal derangement and pain within the temporomandibular joint: a pictorial essay. British Journal of Oral \& Maxillofacial Surgery, 2002, vol. 40, n. 3, p. 220-228. PMid:12054713. http://dx.doi. org/10.1054/bjom.2001.0757

TASAKI, MM., WESTESSON, PL., ISBERG, AM., REN, YF. and TALLENTS, RH. Classification and prevalence of temporomandibular joint disc displacement in patients and symptom-free volunteers. American Journal of Orthodontics and Dentofacial Orthopedics, 1996, vol. 109, n. 3, p. 249-262. http:// dx.doi.org/10.1016/S0889-5406(96)70148-8

TASALI, N., CUBUK, R., ARICAK, M., OZARAR, M., SAYDAM, B., NUR, H. and TUNCBILEK, N. Temporomandibular joint (TMJ) pain revisited with dynamic contrast-enhanced magnetic resonance imaging (DCE-MRI). European Journal of Radiology, 2012, vol. 81, n. 3, p. 603-608. PMid:21300493. http://dx.doi. org/10.1016/j.ejrad.2011.01.044

WANGSRIMONGKOL, T., MANOSUDPRASIT, M., PISEK, P., CHOWCHUEN, P. and CHANTARAMUNGKORN, M. Temporomandibular joint growth adaptation and articular disc positional changes in functional orthopedic treatment: magnetic resonance imaging investigation. Journal of the Medical Association of Thailand, 2012, vol. 95, Supplement 11, p. S106-S115. PMid:23961629. 